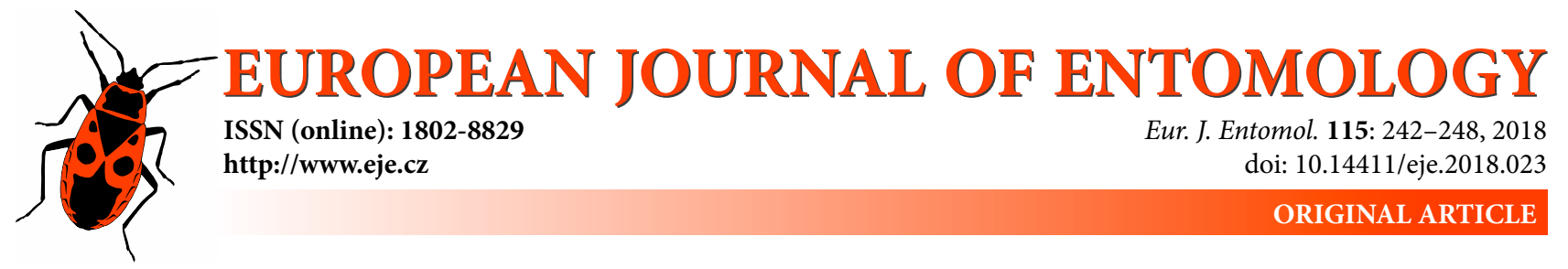

\title{
First mitogenome for the tribe Saccharosydnini (Hemiptera: Delphacidae: Delphacinae) and the phylogeny of three predominant rice planthoppers
}

\author{
YI-XIN HUANG and DAO-ZHENG QIN* \\ Key Laboratory of Plant Protection Resources and Pest Management of the Ministry of Education, Entomological Museum, \\ Northwest A\&F University, Yangling, Shaanxi 712100, China; e-mails: p8370@126.com, qindaozh0426@aliyun.com
}

Key words. Hemiptera, Delphacidae, Delphacinae, Saccharosydne procerus, Sogatella vibix, mitochondrial genome, phylogeny, planthopper, rice

\begin{abstract}
The mitochondrial genome of Saccharosydne procerus (Matsumura) is the first sequenced in the tribe Saccharosydnini (Hemiptera: Delphacidae: Delphacinae). In addition, the mitogenome sequence of Sogatella vibix (Haupt) (in Delphacini) is also sequenced. The Sa. procerus mitochondrial genome is 16,031 bp (GenBank accession no. MG515237) in length, and So. vibix is $16,554 \mathrm{bp}$ (GenBank accession no. MG515238). The existence of purifying selection was indicated by the rate of nonsynonymous and synonymous substitutions. Three species of Delphacini, Laodelphax striatellus (Fallén), Sogatella furcifera (Horváth) and Nilaparvata lugens (Stål), are important pests of rice. The phylogeny of these three rice planthoppers based on the mitochondrial genome sequence was $($ L. striatellus $+($ So. vibix + So. furcifera $))+(N$. muiri $+N$. lugens $)$.
\end{abstract}

\section{INTRODUCTION}

The planthopper subfamily Delphacinae is the most speciose and economically important group in the family Delphacidae. It comprises three tribes (Delphacini, Tropidocephalini and Saccharosydnini) and contains over $80 \%$ of all delphacid species (Asche, 1985; Bourgoin, 2017). Some members in this subfamily are pests of crops or vectors of plant pathogens, causing economic losses widely reported around the world, for example, three species of Delphacini, Laodelphax striatellus (Fallén), Sogatella furcifera (Horváth) and Nilaparvata lugens (Stål) as important pests of rice (e.g. Cai et al., 2003; Wilson, 2005; Grilli, 2006; Grimshaw \& Donaldson, 2007; Wang et al., 2008; Heong et al., 2014; Zhang et al., 2014). Despite several recent studies on the phylogeny of this group (Asche, 1985, 1990; Yang et al., 1987; Emeljanov, 1996; Dijkstra et al., 2003, 2006; Hamilton, 2006; Urban et al., 2010; Huang et al., 2017), more data (including mitochondrial genomes evidence) are still needed to better understand the evolution of Delphacinae.

Insect mitochondrial genomes (mitogenomes) are small, double stranded, circular DNA molecules, ranging in size from 14 to $19 \mathrm{~kb}$. They are composed of 37 genes (13 protein-coding, 22 transfer RNA, and 2 ribosomal RNA genes), and a control region ( $\mathrm{A}+\mathrm{T}$-rich region) that is thought to play a role in the initiation of transcription and replication, and is a source of length variation in the genome (Boore, 1999). In addition, mitogenome sequences are increasingly being utilized in insect identification or biogeographic and phylogenetic studies (Hua et al., 2009; Ma et al., 2012; Nelson et al., 2012; Wang et al., 2015). Here we document the complete mitogenome of Saccharosydne procerus (Matsumura, 1931), which is the first available for the tribe Saccharosydnini. The complete mitochondrial genome of Sogatella vibix (Haupt, 1927) (in Delphacini) was also sequenced. Furthermore, the phylogeny of the Delphacinae based on all the mitogenomes currently in GenBank was reconstructed. The purpose of this study is to investigate the mitogenome differences between members of Delphacini and Saccharosydnini, and provide useful information on the molecular evolution of Delphacinae.

\section{MATERIALS AND METHODS}

\section{Sample preparation and DNA extraction}

Specimens of Saccharosydne procerus and Sogatella vibix were collected from Guangxi Province. All the specimens were stored at $-20^{\circ} \mathrm{C}$ in absolute ethanol prior to DNA extraction. Total genomic DNA was extracted using the cetyltrimethyl ammonium bromide (CTAB) method (Shahjahan et al., 1995).

\footnotetext{
* Corresponding author; e-mail: qindaozh0426@aliyun.com
} 


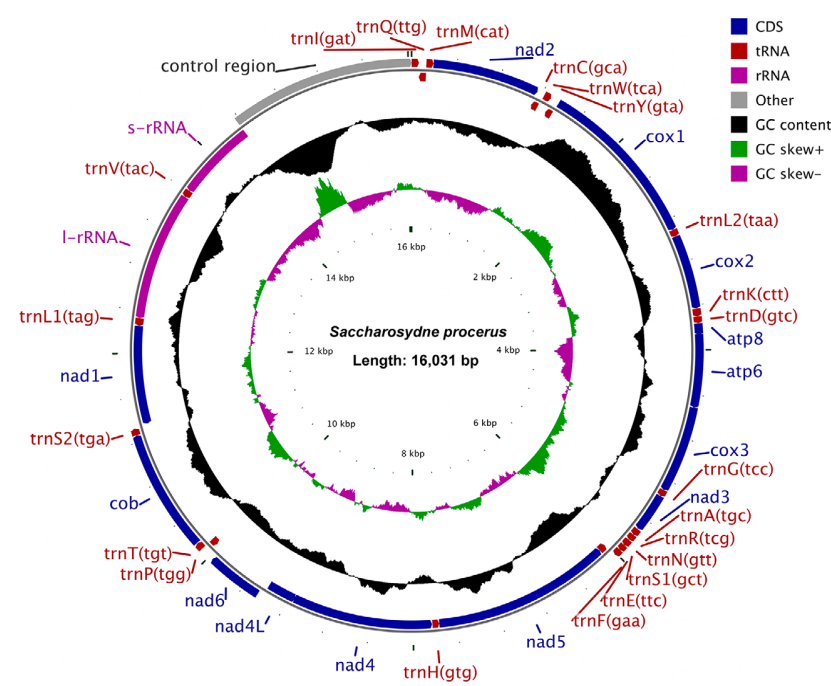

Fig. 1. Mitochondrial genome map of Saccharosydne procerus.

\section{Sequencing and assembly}

A whole genome shotgun (WGS) strategy was used with sequencing on the Illumina Miseq platform. The quality of data was checked by FastQC (Andrews, 2016). The adapters of raw data were removed by AdapterRemoval version 2 (Schubert et al., 2016). SOAPec version 2.01 was used for quality correction, setting K-mer to 17 . Reads with a length of less than $50 \mathrm{bp}$ were excluded. Assembly of the mitochondrial $(\mathrm{mt})$ genome was done using A5-miseq version 2.0 (Coil et al., 2014).

\section{Mitochondrial genome annotation}

The tRNA genes were identified and secondary structures of tRNAs were predicted using MITOS WebSever, setting the parameters with the Invertebrate Mito genetic code (Bernt et al., 2013). Every sequence of tRNA genes was checked separately by eye. Protein-coding genes (PCGs) were identified as open reading frames corresponding to the 13 PCGs in the metazoan $\mathrm{mt}$ genomes. The rRNA genes and control region were identified by the boundary of the tRNA genes and by alignment with other Delphacidae mitogenomes. The mitogenome map was produced using CGView (Grant \& Stothard, 2008).

\section{Comparative analysis}

Base composition and relative synonymous codon usage (RSCU) were analyzed using MEGA 6.0 (Tamura et al., 2013). GC and AT asymmetry were measured in terms of GC and AT skews using the following formulae suggested by Hassa-

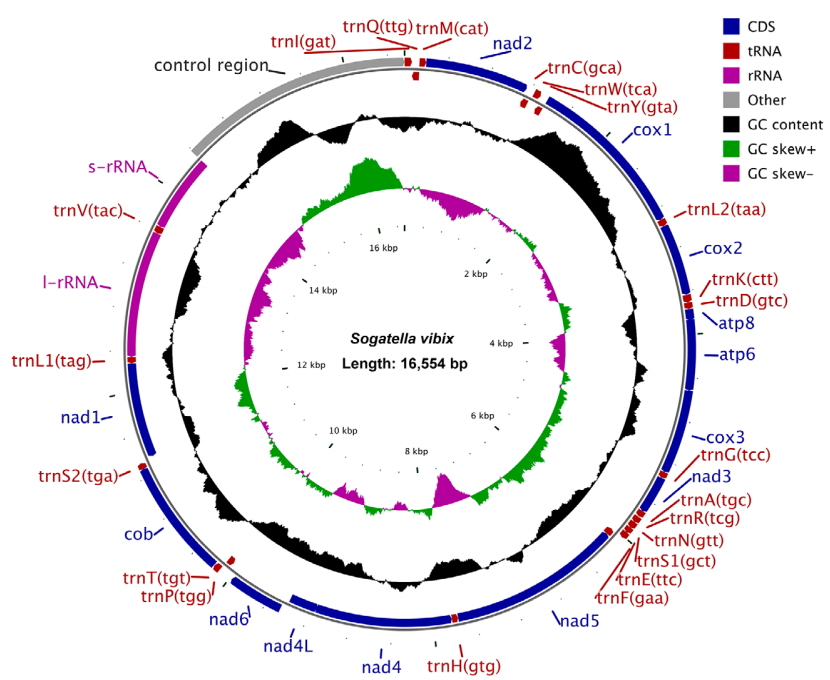

Fig. 2. Mitochondrial genome map of Sogatella vibix.

nin et al. (2005): AT-skew $=(\mathrm{A}-\mathrm{T}) /(\mathrm{A}+\mathrm{T})$ and GC-skew $=$ $(\mathrm{G}-\mathrm{C}) /(\mathrm{G}+\mathrm{C})$. The number of synonymous substitutions per synonymous site (Ks) and the number of nonsynonymous substitutions per nonsynonymous site $(\mathrm{Ka})$ for each concatenated 13 PCGs of Delphacini mitogenome were calculated by DnaSP 5 (Rozas et al., 2003), with stop codons and codons with alignment gaps excluded, using the sequence of Sa. procerus from Saccharosydnini as a reference sequence.

\section{Phylogenetic analysis}

Two newly generated mitogenomes and 12 from GenBank (Table 1) were analyzed in this study, with $\mathrm{Sa}$. procerus selected as an outgroup. Alignment of PCGs was conducted by using MAFFT 7.3.1 using G-INS-I algorithms (Katoh \& Tandley, 2016). Two rRNA segments were aligned by the R-Coffee web server (Moretti, 2008). Subsequently, all alignments were concatenated in a single matrix using DAMBE (Xia, 2013). We used PartitionFinder 1.1.1 (Lanfear et al., 2012) to infer the optimal partitioning strategy; the best-fitting model was selected for each partition using the BIC (Bayesian Information Criterion).

Both ML (Maximum likelihood) and BI (Bayesian inference) analyses were conducted on the concatenated dataset for phylogeny reconstruction. Maximum likelihood analysis was conducted in IQtree v1.4.1 (Lam-Tung et al., 2015) using the best-fit substitution model. An ultrafast bootstrap (UFB) (Bui et al., 2013) of 1000 replications and the SH-aLRT test were used in this analysis to assess branch supports.

Table 1. Taxa included in the phylogenetic analyses in this study.

\begin{tabular}{|c|c|c|c|c|c|c|}
\hline Family & Subfamily & Tribe & Species & Location / Biotype & Accession No. & Reference \\
\hline \multirow[t]{14}{*}{ Delphacidae } & Delphacinae & Delphacini & Laodelphax striatellus & Jiangsu (China) & JX880068 & Zhang et al., 2013 \\
\hline & & & Laodelphax striatellus & Beijing (China) & FJ360695 & Song \& Liang, 2009 \\
\hline & & & Nilaparvata lugens & Biotype 1 & JN563995 & Lv et al., 2015 \\
\hline & & & Nilaparvata lugens & Biotype 2 & JN563996 & Lv et al., 2015 \\
\hline & & & Nilaparvata Iugens & Biotype 3 & JN563997 & Lv et al., 2015 \\
\hline & & & Nilaparvata lugens & Biotype L & KC333654 & Lv \& Ge, unpubl. \\
\hline & & & Nilaparvata lugens & Biotype $Y$ & KC333653 & Lv \& Ge, unpubl. \\
\hline & & & Nilaparvata lugens & Hainan (China) & JX880069 & Zhang et al., 2013 \\
\hline & & & Nilaparvata muiri & Fujian (China) & JN563998 & Lv et al., 2015 \\
\hline & & & Peregrinus maidis & Guangxi (China) & MG049917 & Huang \& Qin, 2017 \\
\hline & & & Sogatella furcifera & Hainan (China) & KC512914 & Zhang et al., 2014 \\
\hline & & & Sogatella furcifera & Yunnan (China) & KC512915 & Zhang et al., 2014 \\
\hline & & & Sogatella vibix & Guangxi (China) & MG515238 & In this study \\
\hline & & Saccharosydnini & Saccharosydne procerus & Guangxi (China) & MG515237 & In this study \\
\hline
\end{tabular}




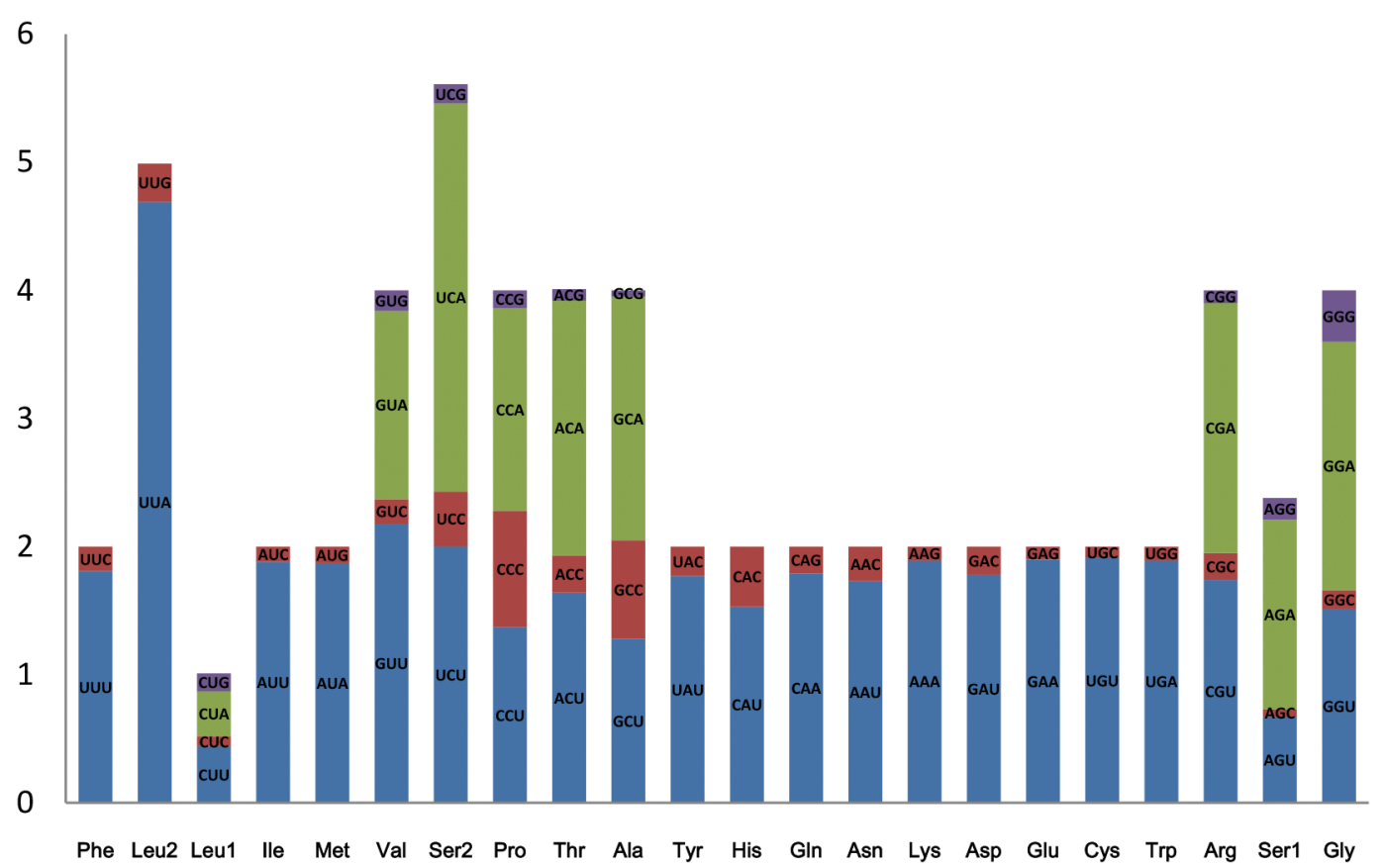

Fig. 3. Relative synonymous codon usage (RSCU) of the mitochondrial genomes of Saccharosydne procerus. The stop codon is not given.

Bayesian inference analysis was conducted using BEAST 1.8.0 (Drummond et al., 2012). Chains were run for 20 million generations, with sampling every 2000 generations. Tracer 1.6.0 (Rambaut et al., 2014) was used to verify the posterior distribution and to ensure effective sample sizes (ESSs) $>200$ from the Markov Chain Monte Carlo (MCMC) output. TreeAnnotator in the BEAST package was used to summarize tree data with "median height". The first $25 \%$ of samples were discarded as burn-in and the remaining samples were used to generate a $50 \%$ majority rule consensus tree. FigTree v.1.3.1 (Rambaut, 2009) was used to view the resulting trees.

\section{RESULTS AND DISCUSSION}

The $\mathrm{Sa}$. procerus mitochondrial genome (GenBank accession no. MG515237) is 16,031 bp in length (Fig. 1), and the overall nucleotide composition exhibits a high $\mathrm{A}+\mathrm{T}$

Table 2. Nucleotide composition of the Saccharosydne procerus mitochondrial genome.

\begin{tabular}{lcccccccc}
\hline & & \multicolumn{6}{c}{ Percentage of nucleotides } \\
\cline { 3 - 9 } Feature & Length & A & C & G & T & G + C $\begin{array}{c}\text { AT- } \\
\text { skew }\end{array}$ & $\begin{array}{c}\text { GC- } \\
\text { skew }\end{array}$ \\
\hline Whole genome & 16031 & 45.6 & 11.9 & 7.6 & 34.9 & 19.5 & 0.13 & -0.22 \\
PCGs & 10835 & 45.3 & 12.8 & 8.0 & 33.9 & 20.8 & 0.14 & -0.23 \\
tRNAs & 1404 & 43.9 & 10.8 & 9.3 & 36.0 & 20.1 & 0.10 & -0.07 \\
rRNAs & 1971 & 45.2 & 12.0 & 6.6 & 36.2 & 18.6 & 0.11 & -0.29 \\
AT-rich region & 1662 & 48.8 & 7.5 & 4.5 & 39.2 & 12.0 & 0.11 & -0.25 \\
\hline
\end{tabular}

Table 3. Nucleotide composition of the Sogatella vibix mitochondrial genome.

\begin{tabular}{lcccccccc}
\hline \multirow{2}{*}{ Feature } & & \multicolumn{4}{c}{ Percentage of nucleotides } \\
\cline { 3 - 8 } & Length & $\mathrm{A}$ & $\mathrm{C}$ & $\mathrm{G}$ & $\mathrm{T}$ & $\mathrm{G}+\mathrm{C}$ & $\begin{array}{c}\text { AT- } \\
\text { skew }\end{array}$ & $\begin{array}{c}\text { GC- } \\
\text { skew }\end{array}$ \\
\hline Whole genome & 16554 & 41.8 & 13.9 & 10.1 & 34.2 & 24.0 & $0.10-0.16$ \\
PCGs & 10858 & 42.4 & 14.4 & 10.2 & 33.0 & 24.6 & 0.12 & -0.17 \\
tRNAs & 1395 & 42.3 & 11.9 & 10.2 & 35.6 & 22.1 & $0.09-0.08$ \\
rRNAs & 1976 & 42.8 & 14.8 & 7.7 & 34.7 & 22.5 & $0.10-0.32$ \\
AT-rich region & 2167 & 36.5 & 12.2 & 11.9 & 39.4 & 24.1 & $-0.04-0.01$ \\
\hline
\end{tabular}

Table 4. Organization of the mitogenome of Saccharosydne procerus.

\begin{tabular}{|c|c|c|c|c|c|c|}
\hline \multirow{2}{*}{ Name } & \multirow{2}{*}{ Product } & \multirow{2}{*}{ Strand } & \multirow{2}{*}{ Location } & \multicolumn{3}{|c|}{ Codon } \\
\hline & & & & Start & Stop & Anti \\
\hline trnl & tRNA-Ile & $\mathrm{J}$ & $1-65$ & & & GAT \\
\hline $\operatorname{trn} Q$ & tRNA-GIn & $\mathrm{N}$ & $67-132$ & & & TTG \\
\hline $\operatorname{trnM}$ & tRNA-Met & $\mathrm{J}$ & $132-195$ & & & CAT \\
\hline nad2 & $\mathrm{NADH} 2$ & $\mathrm{~J}$ & $196-1155$ & ATT & TAA & \\
\hline $\operatorname{trn} C$ & tRNA-Cys & $\mathrm{N}$ & $1154-1214$ & & & GCA \\
\hline $\operatorname{trn} W$ & tRNA-Trp & $\mathrm{J}$ & $1223-1287$ & & & TCA \\
\hline $\operatorname{trn} Y$ & tRNA-Tyr & $\mathrm{N}$ & 1302-1362 & & & GTA \\
\hline $\operatorname{cox} 1$ & CoX1 & $\mathrm{J}$ & 1368-2901 & ATG & $\mathrm{T}$ & \\
\hline $\operatorname{trn} L 2$ & tRNA-Leu & $\mathrm{J}$ & 2902-2965 & & & TAA \\
\hline $\operatorname{cox} 2$ & $\operatorname{cox} 2$ & $\mathrm{~J}$ & 2996-3631 & ATT & TAA & \\
\hline trnK & tRNA-Lys & $\mathrm{J}$ & $3634-3703$ & & & CTT \\
\hline $\operatorname{trn} D$ & tRNA-Asp & $\mathrm{J}$ & $3704-3763$ & & & GTC \\
\hline atp8 & ATP8 & $\mathrm{J}$ & $3764-3865$ & ATT & TAA & \\
\hline atp6 & ATP6 & $\mathrm{J}$ & 3859-4513 & ATG & $\mathrm{T}$ & \\
\hline $\operatorname{cox} 3$ & cox3 & $\mathrm{J}$ & $4514-5294$ & ATG & $\mathrm{T}$ & \\
\hline $\operatorname{trn} G$ & tRNA-Gly & $\mathrm{J}$ & 5295-5355 & & & TCC \\
\hline nad3 & $\mathrm{NADH} 3$ & $\mathrm{~J}$ & $5356-5706$ & ATT & TAA & \\
\hline $\operatorname{trn} A$ & tRNA-Ala & $\mathrm{J}$ & $5712-5774$ & & & TGC \\
\hline $\operatorname{trnR}$ & tRNA-Arg & $\mathrm{J}$ & $5775-5833$ & & & TCG \\
\hline $\operatorname{trnN}$ & tRNA-Asn & $\mathrm{J}$ & 5835-5897 & & & GTT \\
\hline $\operatorname{trnS1}$ & tRNA-Ser & $\mathrm{J}$ & $5897-5954$ & & & GCT \\
\hline $\operatorname{trn} E$ & tRNA-Glu & $\mathrm{J}$ & 5954-6015 & & & TTC \\
\hline $\operatorname{trnF}$ & tRNA-Phe & $\mathrm{N}$ & 6020-6086 & & & GAA \\
\hline nad5 & $\mathrm{NADH} 5$ & $\mathrm{~N}$ & $6087-7758$ & ATG & $\mathrm{T}$ & \\
\hline $\operatorname{trnH}$ & tRNA-His & $\mathrm{N}$ & 7759-7822 & & & GTG \\
\hline nad4 & $\mathrm{NADH} 4$ & $\mathrm{~N}$ & $7826-9142$ & ATG & TAA & \\
\hline nad4l & NADH4L & $\mathrm{N}$ & $9136-9408$ & ATG & TAG & \\
\hline nad6 & NADH6 & $\mathrm{J}$ & $9458-9964$ & ATA & TAA & \\
\hline $\operatorname{trn} P$ & tRNA-Pro & $\mathrm{N}$ & 10029-10092 & & & TGG \\
\hline $\operatorname{trn} T$ & tRNA-Thr & $\mathrm{J}$ & 10094-10157 & & & TGT \\
\hline cytb & CYTB & $\mathrm{J}$ & 10162-11262 & ATG & TAA & \\
\hline trnS2 & tRNA-Ser & $\mathrm{J}$ & $11264-11325$ & & & TGA \\
\hline nad1 & $\mathrm{NADH} 1$ & $\mathrm{~N}$ & $11341-12256$ & ATG & $\mathrm{T}$ & \\
\hline $\operatorname{trnL1}$ & tRNA-Leu & $\mathrm{N}$ & $12258-12328$ & & & TAG \\
\hline$r r n L$ & 16S rRNA & $\mathrm{N}$ & $12329-13545$ & & & \\
\hline $\operatorname{trn} V$ & tRNA-Val & $\mathrm{N}$ & $13546-13615$ & & & TAC \\
\hline$r r n S$ & 12S rRNA & $\mathrm{N}$ & $13616-14369$ & & & \\
\hline AT-rich & & & 14370-16031 & & & \\
\hline
\end{tabular}




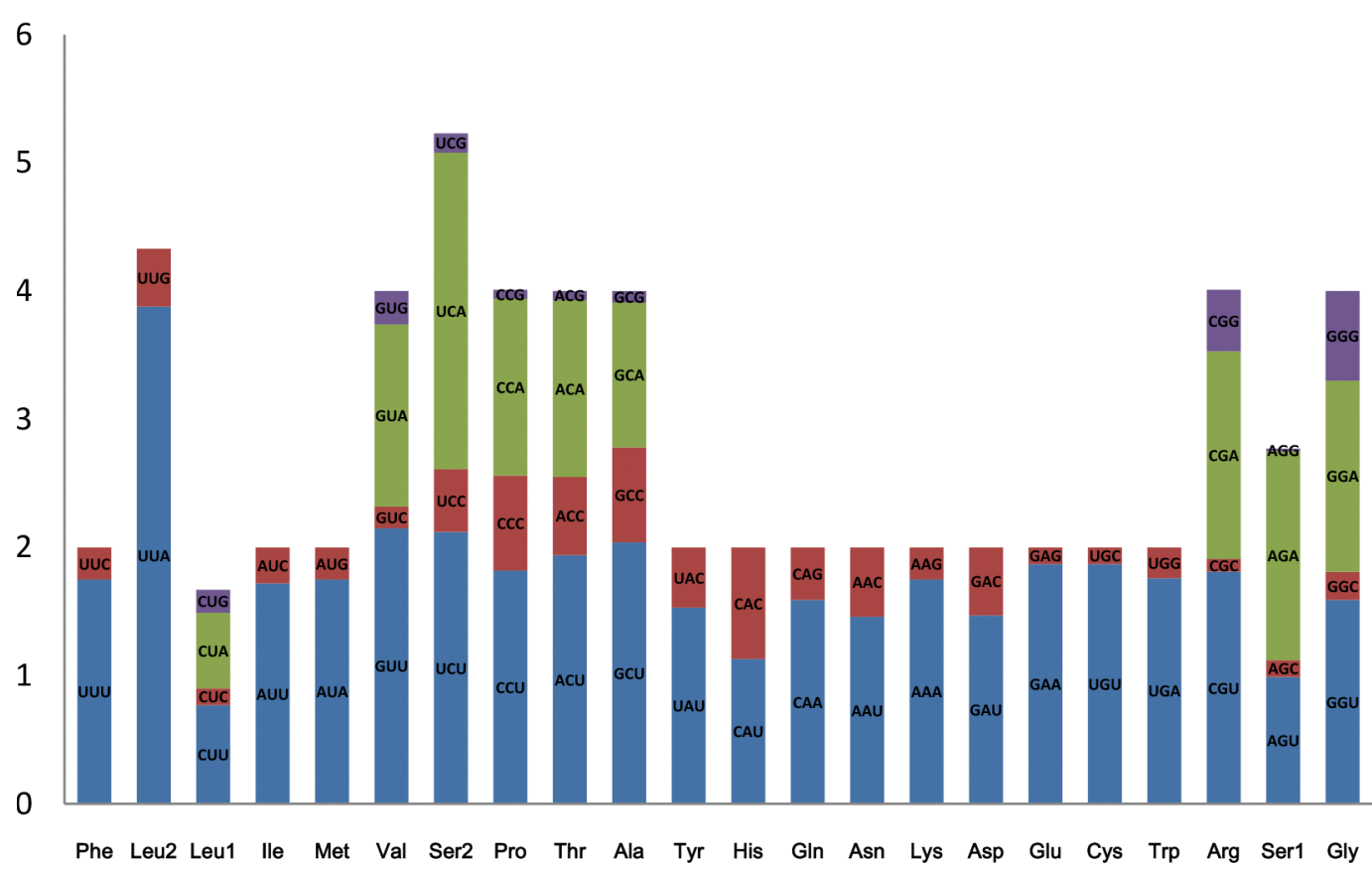

Fig. 4. Relative synonymous codon usage (RSCU) of the mitochondrial genomes of Sogatella vibix. The stop codon is not given.

content of $80.5 \%$ (Table 2). The mitogenome of So. vibix (GenBank accession no. MG515238) is 16,554 bp long with an $\mathrm{A}+\mathrm{T}$ content of $76.0 \%$ (Table 3 ), likewise heavily biased toward the A and T nucleotides (Fig. 2). The mitogenomes of both species encode a complete set of 37 genes (Tables 4-5) which are usually found in animal mitogenomes, consisting of 13 protein-coding genes (PCG), 2 ribosomal RNA (rRNA) genes and 22 transfer RNA (tRNA) genes (Cameron, 2014). The gene arrangements in the mitochondrial genomes of Sa. procerus and So. vibix are conserved, similar to other mitogenomes of Delphacidae, with the exception of Nilaparvata lugens (Stål). Zhang et al. (2013) found three trnC genes in N. lugens, but only one trnC gene was found by Lv et al. (2015) which corresponds to most hemipteran insects sequenced so far (Wang et al., 2015).

Most PCGs share the start codon ATT or ATG, with nad6 of Sa. procerus starting with ATA. Four genes of So. vibix (cox1, atp6, cox3, nad5) and fives genes of Sa. procerus (cox1, atp6 , cox3, nad5, nad1) use the incomplete stop codon T. Four genes of So. vibix (cox2, nad4l, cytb, nad1) and nad $4 \mathrm{l}$ of $\mathrm{Sa}$. procerus use TAG. The remaining PCGs

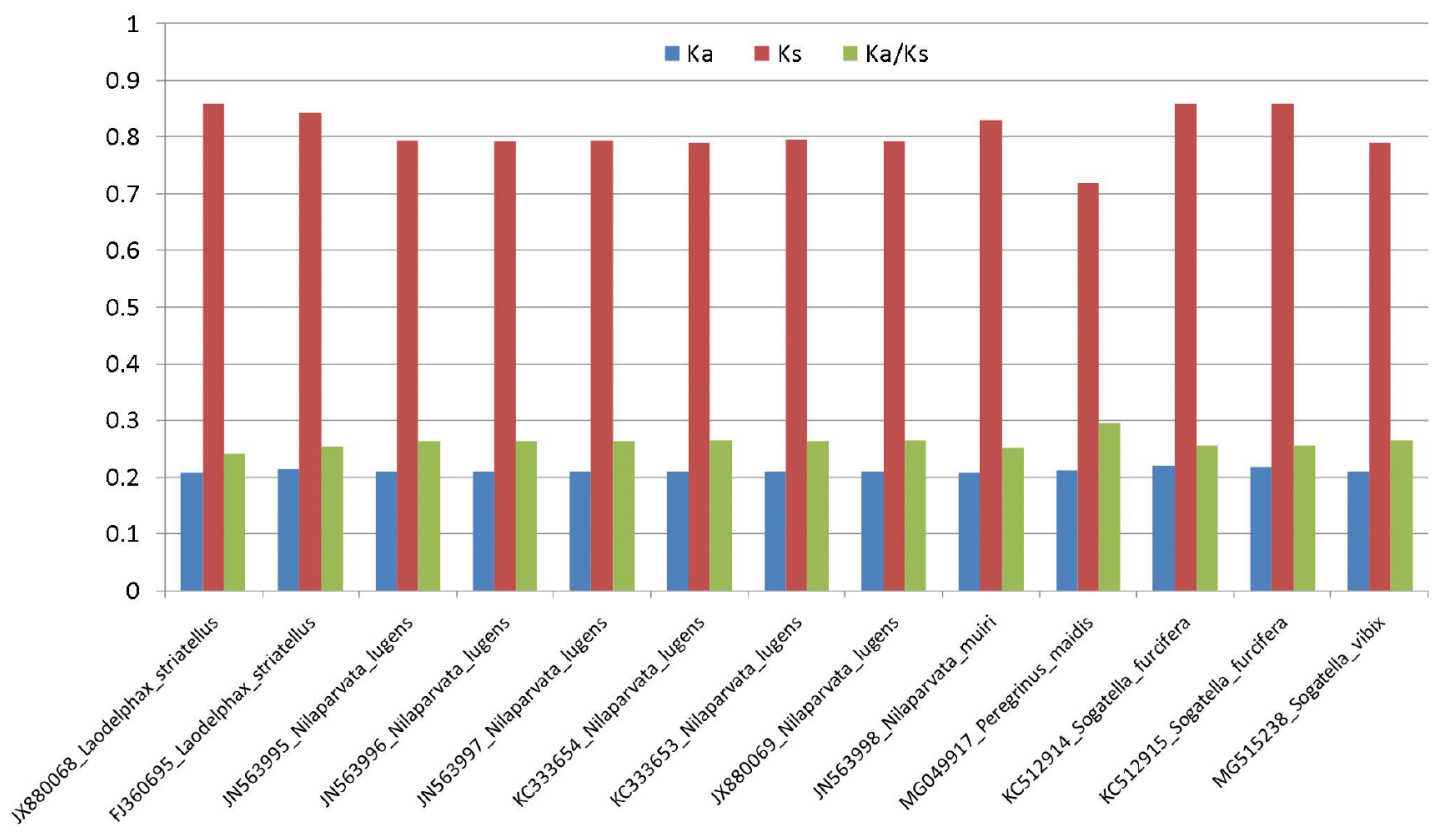

Fig. 5. Evolutionary rates of Delphacini mitochondrial genomes. The number of nonsynonymous substitutions per nonsynonymous site (Ka), the number of synonymous substitutions per synonymous site (Ks), and the ratio of Ka/Ks for each Delphacini mitochondrial genome are given, using that of Saccharosydne procerus as a reference sequence. 


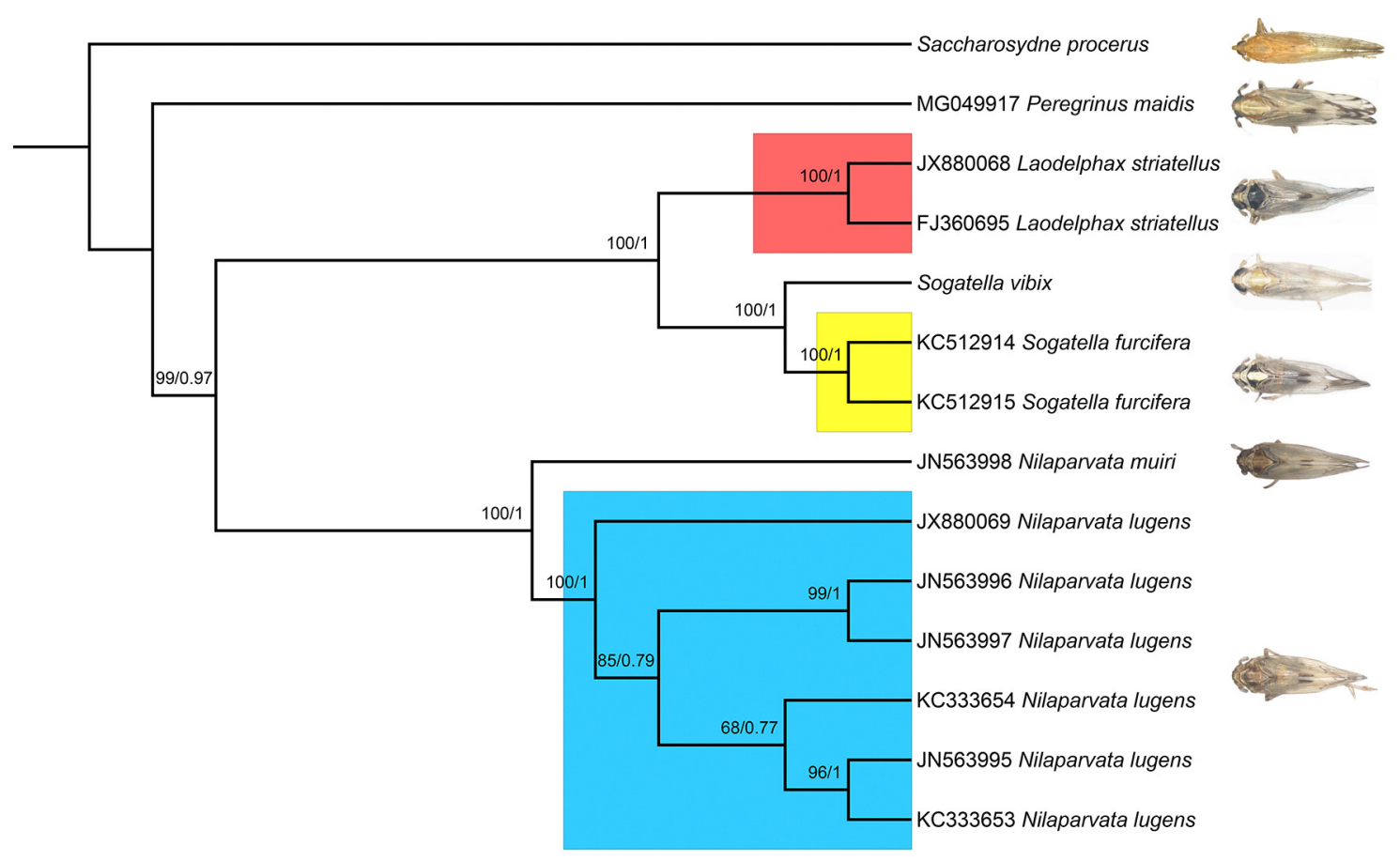

Fig. 6. Phylogenetic tree of three predominant rice planthoppers obtained from ML analysis based on concatenated data of 13 PCGs and two rRNA genes. The numbers at nodes indicate ML bootstrap values/Bayesian posterior probabilities, respectively. Accession numbers are given for species obtained from GenBank.

use the stop codon TAA. The stop codon of nadl in $S a$. procerus $(\mathrm{T})$ is different from those in Delphacini (TAA or TAG). This suggests that during evolution the nadl gene in Sa. procerus acquired a different mechanism for transcription termination. Further genome sequencing is needed to find out whether this feature exists only in Sa. procerus or in the tribe Saccharosydnini. The use of anti-codons for 22 tRNAs are all the same between So. vibix and Sa. procerus.

The relative synonymous codon usage (RSCU) of $\mathrm{Sa}$. procerus and So. vibix are shown in Figs 3-4. The codon usage in these mitogenomes shows a high AT content. The most frequently used amino acids were Phe, Leu and Ile, while TTT (Phe), TTA (Leu) and ATT (Ile) were the most frequently utilized codons. All three of these most frequently utilized codons are composed of A and T. Additionally, it is obvious that the preferred codon usage is A or $\mathrm{T}$ in the third position rather than $\mathrm{G}$ and $\mathrm{C}$. Almost all of the frequently used codons ended with $\mathrm{A}$ or $\mathrm{T}$, which may contribute to the significant bias towards $\mathrm{A}$ and $\mathrm{T}$.

The rate of nonsynonymous substitutions $(\mathrm{Ka})$, synonymous substitutions (Ks), and the ratio of $\mathrm{Ka} / \mathrm{Ks}$ were calculated for PCGs of each delphacine mitogenome with $\mathrm{Sa}$. procerus as the reference sequence (Fig. 5). All of the Ka, $\mathrm{Ks}$ and the ratios of $\mathrm{Ka} / \mathrm{Ks}$ values were less than 1 , indicating the existence of purifying selection in these species.

Saccharosydne procerus (tribe Saccarosydnini) was selected as the outgroup based on results of previous analyses that placed this tribe (plus Tropidocephalini) as sister to Delphacini (Asche, 1985, 1990; Urban et al., 2010; Huang et al., 2017). Peregrinus maidis was also included to test the polarity of the phylogeny. The result placed $P$. maidis as sister to the remaining Delphacini, which is concordant with our previous study (Huang et al., 2017). We therefore think the use of $\mathrm{Sa}$. procerus as the outgroup taxon is appropriate.

The phylogenetic analyses of ML and BI based on mitogenome datasets yield two identical topologies (Fig. 6) when rooted with $\mathrm{Sa}$. procerus (of Saccharosydnini); remaining species form the tribe Delphacini, with $P$. maidis being sister to the remaining species. The conformation of the clade containing the three rice planthoppers (L. striatellus, So. furcifera and N. lugens) was (L. striatellus $+($ So. vibix + So. furcifera $))+(N$. muiri $+N$. lugens $)$. Moreover, the relationships among biotypes of $N$. lugens were recovered.

This study documents the first mitogenome of Saccharosydnini and the mitogenome of So. vibix, which both contain 37 typical metazoan mitochondrial genes and retain the organization of the most other Delphacidae mitogenomes. The phylogeny based on more taxa is needed to better understand the evolution of Delphacidae. Therefore, more mitogenomes need to be sequenced in further studies.

ACKNOWLEDGEMENTS. The authors gratefully acknowledge J.R. Schrock (Emporia State University, Emporia, USA) for reviewing the manuscript. This work was supported by the National Natural Science Foundation of China (Nos 31172126, 31672340 , 31750002).

\section{REFERENCES}

ANDREwS S. 2016: FASTQC. URL: http://www. bioinformatics. babraham.ac.uk/projects/fastqc.

Asche M. 1985: Zur Phylogenie der Delphacidae Leach, 1815 (Homoptera: Cicadina: Fulgoromorpha). - Marburg. Entomol. Publ. 2: 1-910. 
Table 5. Organization of the mitogenome of Sogatella vibix.

\begin{tabular}{|c|c|c|c|c|c|c|}
\hline \multirow{2}{*}{ Name } & \multirow{2}{*}{ Product } & \multirow{2}{*}{ Strand } & \multirow{2}{*}{ Location } & \multicolumn{3}{|c|}{ Codon } \\
\hline & & & & Start & Stop & Anti \\
\hline trnl & tRNA-Ile & J & $1-68$ & & & GAT \\
\hline $\operatorname{trn} Q$ & tRNA-GIn & $\mathrm{N}$ & $71-138$ & & & TTG \\
\hline $\operatorname{trnM}$ & tRNA-Met & $J$ & $138-199$ & & & CAT \\
\hline nad2 & NADH2 & $\mathrm{J}$ & 200-1156 & ATT & TAA & \\
\hline $\operatorname{trn} C$ & tRNA-Cys & $\mathrm{N}$ & 1155-1219 & & & GCA \\
\hline $\operatorname{trn} W$ & tRNA-Trp & J & $1236-1300$ & & & TCA \\
\hline $\operatorname{trn} Y$ & tRNA-Tyr & $\mathrm{N}$ & 1310-1371 & & & GTA \\
\hline $\operatorname{cox} 1$ & cox 1 & $\mathrm{~J}$ & 1373-2906 & ATG & $\mathrm{T}$ & \\
\hline $\operatorname{trn} L 2$ & tRNA-Leu & J & 2907-2971 & & & TAA \\
\hline $\operatorname{cox} 2$ & $\mathrm{coX} 2$ & J & 2972-3634 & ATT & TAG & \\
\hline $\operatorname{trnK}$ & tRNA-Lys & $J$ & $3636-3706$ & & & CTT \\
\hline $\operatorname{trn} D$ & tRNA-Asp & $\mathrm{J}$ & $3707-3768$ & & & GTC \\
\hline atp8 & ATP8 & J & $3769-3870$ & ATT & TAA & \\
\hline atp6 & ATP6 & J & $3864-4518$ & ATG & $\mathrm{T}$ & \\
\hline $\operatorname{cox} 3$ & $\mathrm{cox} 3$ & $J$ & $4519-5299$ & ATG & $\mathrm{T}$ & \\
\hline $\operatorname{trn} G$ & tRNA-Gly & $J$ & $5300-5359$ & & & TCC \\
\hline nad3 & NADH3 & J & $5360-5710$ & ATT & TAA & \\
\hline $\operatorname{trn} A$ & tRNA-Ala & J & $5710-5770$ & & & TGC \\
\hline $\operatorname{trnR}$ & tRNA-Arg & $\mathrm{J}$ & $5775-5835$ & & & TCG \\
\hline $\operatorname{trn} N$ & tRNA-Asn & J & 5835-5898 & & & GTT \\
\hline $\operatorname{trnS1}$ & tRNA-Ser & J & 5898-5954 & & & GCT \\
\hline $\operatorname{trnE}$ & tRNA-Glu & J & 5954-6016 & & & TTC \\
\hline $\operatorname{trnF}$ & tRNA-Phe & $\mathrm{N}$ & 6017-6083 & & & GAA \\
\hline nad5 & NADH5 & $\mathrm{N}$ & 6084-7758 & ATG & $\mathrm{T}$ & \\
\hline $\operatorname{trnH}$ & tRNA-His & $\mathrm{N}$ & 7759-7819 & & & GTG \\
\hline nad4 & NADH4 & $\mathrm{N}$ & $7820-9142$ & ATG & TAA & \\
\hline nad4I & NADH4L & $\mathrm{N}$ & 9136-9408 & ATG & TAG & \\
\hline nad6 & NADH6 & $\mathrm{J}$ & 9458-9979 & ATT & TAA & \\
\hline $\operatorname{trn} P$ & tRNA-Pro & $N$ & 10055-10116 & & & TGG \\
\hline $\operatorname{trn} T$ & tRNA-Thr & J & 10119-10182 & & & TGT \\
\hline cytb & CYTB & $J$ & $10187-11290$ & ATG & TAG & \\
\hline $\operatorname{trn} S 2$ & tRNA-Ser & J & 11289-11344 & & & TGA \\
\hline nad1 & NADH1 & $\mathrm{N}$ & 11362-12279 & ATG & TAG & \\
\hline $\operatorname{trn} L 1$ & tRNA-Leu & $\mathrm{N}$ & 12281-12342 & & & TAG \\
\hline$r r n L$ & $16 \mathrm{~S}$ rRNA & $\mathrm{N}$ & 12343-13569 & & & \\
\hline $\operatorname{trnV}$ & tRNA-Val & $\mathrm{N}$ & 13570-13638 & & & TAC \\
\hline$r r n S$ & $12 \mathrm{~S}$ rRNA & $\mathrm{N}$ & 13639-14387 & & & \\
\hline AT-rich & & & 14388-16554 & & & \\
\hline
\end{tabular}

Asche M. 1990: Vizcayinae, a new subfamily of Delphacidae with revision of Vizcaya Muir (Homoptera: Fulgoroidea) - a significant phylogenetic link. - Bishop Mus. Occas. Pap. 30: 154-187.

Bernt M., Donath A., Jühling F., Externbrink F., Florentz C., Fritzsch G., PÜtz J., Middendorf M. \& Stadler P.F. 2013: MITOS: Improved de novo metazoan mitochondrial genome annotation. - Mol. Phylogenet. Evol. 69: 313-319.

Boore J.L. 1999: Animal mitochondrial genomes. - Nucl. Acids Res. 27: 1767-1780.

BouRgoIn T. 2017: FLOW (Fulgoromorpha Lists on the Web): A World Knowledge Base Dedicated to Fulgoromorpha. URL: http://hemipteradatabases.org/flow.

Bui Q.M., Minh A.T.N. \& ARNDT H. 2013: Ultrafast approximation for phylogenetic bootstrap. - Mol. Biol. Evol. 30: 1188 1195.

Cai L.J., Ma X.Z., Kang L., Deng K.J., Zhao S.Y. \& Li C.B. 2003: Detecting rice stripe virus (RSV) in the small brown planthopper (Laodelphax striatellus) with high specificity by RT-PCR. - J. Virol. Meth. 112: 115-120.

CAMERON S.L. 2014: Insect mitochondrial genomics: implications for evolution and phylogeny. - Annu. Rev. Entomol. 59: 95-117.
CoIL D., Jospin G. \& DARLING A.E. 2014: A5-miseq: an updated pipeline to assemble microbial genomes from Illumina MiSeq data. - Bioinformatics 31: 587-589.

Dijkstra E., Rubio J.M. \& Post R.J. 2003: Resolving relationships over a wide taxonomic range in Delphacidae (Homoptera) using the COI gene. - Syst. Entomol. 28: 89-100.

Dijkstra E., Slotman M.A. \& Post R.J. 2006: Resolution of phylogenetic relationships of the major subfamilies of the Delphacidae (Homoptera: Fulgoroidea) using the mitochondrial ribosomal DNA. - Insect Sci. 13: 167-177.

Drummond A.J., Suchard M.A., Xie D. \& Rambaut A. 2012: Bayesian phylogenetics with BEAUti and the BEAST 1.7. Mol. Biol. Evol. 29: 1969-1973.

EMELJANOv A.F. 1996: On the question of the classification and phylogeny of the Delphacidae (Homoptera, Cicadina) with reference to larval characters. - Entomol. Rev. 75: 134-150.

Grant J.R. \& Stothard P. 2008: The CGView Server: a comparative genomics tool for circular genomes. - Nucl. Acid. Res. 36: $181-184$.

GRILLI M.P. 2006: Effect of local land use on populations of a disease vector planthopper. - Environ. Entomol. 35: 1254-1263.

GRIMSHAW J.F. \& DonaldSON J.F. 2007: Records of two sugarcane pests Eumetopina flavipes Muir (Hemiptera: Delphacidae) and Chilo terrenellus Pagenstecher (Lepidoptera: Pyralidae) from Torres Strait and far north Queensland. - Austral Entomol. 46: $35-39$.

Hamilton K.G.A. 2006: The planthopper genus Stenocranus in Canada: implications for classification of Delphacidae (Hemiptera). - Can. Entomol. 138: 493-503.

Hassanin A., Léger N. \& Deutsch J. 2005: Evidence for multiple reversals of asymmetric mutational constraints during the evolution of the mitochondrial genome of Metazoa, and consequences for phylogenetic inferences. - Syst. Biol. 54: 277-298.

Haupt H. 1927: Homoptera Palestinae I. — Bull. Palest. Agricult. Exp. Stat. 8: 5-43.

Heong K.L., Cheng J.A. \& Escalada M.M. 2014: Rice Planthoppers: Ecology, Management, Socio Economics and Policy. Springer \& Zhejiang University Press, Hangzhou, 231 pp.

Hua J.M., Li M., Dong P.Z., Cui Y., XIE Q. \& Bu W.J. 2009: Phylogenetic analysis of the true water bugs (Insecta: Hemiptera: Heteroptera: Nepomorpha): Evidence from mitochondrial genomes. - BMC Evol. Biol. 9: 134, 11 pp.

HuANG Y.X. \& QIN D.Z. 2017: The complete mitochondrial genome sequence of the corn planthopper, Peregrinus maidis (Hemiptera: Fulgoroidea). — Mitochon. DNA (B) 2: 783-784.

Huang Y.X., Zheng L.F., Bartlett C.R. \& Qin D.Z. 2017: Resolving phylogenetic relationships of Delphacini and Tropidocephalini (Hemiptera: Delphacidae: Delphacinae) as inferred from four genetic loci. - Sci. Rep. 7: 3319, 11 pp.

KATOH K.S. \& TANDLEY D.M. 2016: A simple method to control over-alignment in the MAFFT multiple sequence alignment program. - Bioinformatics 32: 1933-1942.

LAm-Tung N., HeIKo A.S., ARndt H. \& Bui Q.M. 2015: IQ-TREE: a fast and effective stochastic algorithm for estimating maximum likelihood phylogenies. - Mol. Biol. Evol. 32: 268-274.

Lanfear R., Calcott B., Ho S. \& Guindon S. 2012: PartitionFinder: combined selection of partitioning schemes and substitution models for phylogenetic analyses. - Mol. Biol. Evol. 29: $1695-1701$.

Lv L., Peng X., Jing S., Liu B., Zhu L. \& He G. 2015: Intraspecific and interspecific variations in the mitochondrial genomes of Nilaparvata (Hemiptera: Delphacidae). - J. Econ. Entomol. 108: 2021-2029. 
Ma C., Yang P.C., Jiang F., Chapuis M.P., Shall Y., Sword G.A. \& KANG L. 2012: Mitochondrial genomes reveal the global phylogeography and dispersal routes of the migratory locust. - Mol. Ecol. 21: 4344-4458.

Matsumura S. 1931: 6000 Illustrated Insects of Japan Empire. Tokyo, $1497 \mathrm{pp}$.

Moretti S., Wilm A., Higgins D.G., Xenarios I. \& Notredame C. 2008: R-Coffee: a web server for accurately aligning noncoding RNA sequences. - Nucl. Acids Res. 36: 10-13.

Nelson L.A., Lambkin C.L., Batterham P., Wallman J.F., Dowton M., Whiting M.F., Yeates D.K. \& Cameron S.L. 2012: Beyond barcoding: a mitochondrial genomics approach to molecular phylogenetics and diagnostics of blowflies (Diptera: Calliphoridae). - Gene 511: 131-142.

RAMBAUT A. 2009: FigTree v1.3.1. URL: http://tree.bio.ed.ac.uk/ software/figtree.

Rambaut A., Suchard M.A., Xie D. \& Drummond A.J. 2014: Tracer v1.6. URL: http://beast.bio.ed.ac.uk/Tracer.

Rozas J., Sánchezdelbarrio J.C., Messeguer X. \& Rozas R. 2003: DnaSP, DNA polymorphism analyses by the coalescent and other methods. - Bioinformatics 19: 2496-2497.

Schubert M., Lindgreen S. \& Orlando L. 2016: AdapterRemoval v2: rapid adapter trimming, identification, and read merging. — BMC Res. Notes 9(1): 88, 7 pp.

Shahjahan R.M., Hughes K.J., Leopold R.A. \& DeVault J.D. 1995: Lower incubation temperature increases yield of insect genomic DNA isolated by the CTAB method. - Bio. Techniques 19: 333-334.

Song N. \& Liang A.P. 2009: Complete mitochondrial genome of the small brown planthopper, Laodelphax striatellus (Delphacidae: Hemiptera), with a novel gene order. - Zool. Sci. 26: 851-860.

Tamura K., Stecher G., Peterson D., Filipski A. \& Kumar S. 2013: MEGA6: Molecular evolutionary genetics analysis version 6.0. - Mol. Biol. Evol. 30: 2725-2729.
Urban J.M., Bartlett C.R. \& Cryan J.R. 2010: Evolution of Delphacidae (Hemiptera: Fulgoroidea): combined-evidence phylogenetics reveals importance of grass host shifts. - Syst. Entomol. 35: 678-691.

Wang Y., Chen J., Zhu Y.C., Ma C., Huang Y. \& Shen J. 2008: Susceptibility to neonicotinoids and risk of resistance development in the brown planthopper, Nilaparvata lugens (Stål) (Homoptera: Delphacidae). — Pest Manag. Sci. 64: 12781284.

Wang Y., Chen J., Jiang L.Y. \& Qiao G.X. 2015: Hemipteran mitochondrial genomes: features, structures and implications for phylogeny. - Int. J. Mol. Sci. 16: 12382-12404.

WILSON S.W. 2005: Keys to the families of Fulgoromorpha with emphasis on planthoppers of potential economic importance in the southeastern United States (Hemiptera: Auchenorrhyncha). - Fla Entomol. 88: 464-481.

XIA X. 2013: DAMBE5: a comprehensive software package for data analysis in molecular biology and evolution. - Mol. Biol. Evol. 92: 1-27.

YANG J.T., YANG C.T. \& SHAO K.T. 1987: Numerical taxonomic studies on the Asiracinae and Tropidocephalini (Fulgoroidea: Delphacidae) from Taiwan. - Bull. Inst. Zool. Acad. Sin. 26: 215-230.

Zhang K.J., Zhu W.C., Rong X., Zhang Y.K., Ding X.L., Liu J., Chen D.S., Du Y. \& Hong X.Y. 2013: The complete mitochondrial genomes of two rice planthoppers, Nilaparvata lugens and Laodelphax striatellus: conserved genome rearrangement in Delphacidae and discovery of new characteristics of atp8 and tRNA genes. - BMC Genomics 14: 417, 12 pp.

Zhang K.J., Zhu W.C., Rong X., Liu J., Ding X.L. \& Hong X.Y. 2014: The complete mitochondrial genome sequence of Sogatella furcifera (Horváth) and a comparative mitogenomic analysis of three predominant rice planthoppers. - Gene 533: 100-109.

Received December 14, 2017; revised and accepted April 10, 2018 Published online May 30, 2018 